\title{
BMJ Open The influence of complexity: a bibliometric analysis of complexity science in healthcare
}

\author{
Kate Churruca, ${ }^{\odot}$ Chiara Pomare, ${ }^{\odot}$ Louise A Ellis, ${ }^{\odot}$ Janet C Long, \\ Jeffrey Braithwaite
}

To cite: Churruca K, Pomare C, Ellis $L A$, et al. The influence of complexity: a bibliometric analysis of complexity science in healthcare. BMJ Open 2019;9:e027308. doi:10.1136/ bmjopen-2018-027308

- Prepublication history and additional material for this paper are available online. To view these files, please visit the journal online (http://dx.doi. org/10.1136/bmjopen-2018027308).

Received 16 0ctober 2018 Revised 8 January 2019 Accepted 22 February 2019

D Check for updates

(c) Author(s) (or their employer(s)) 2019. Re-use permitted under CC BY-NC. No commercial re-use. See rights and permissions. Published by BMJ.

Australian Institute of Health Innovation, Macquarie University, Sydney, NSW, Australia

Correspondence to

Dr Kate Churruca;

kate.churruca@mq.edu.au

\section{ABSTRACT}

Objectives To analyse trends in the academic literature applying complexity science to healthcare, focusing specifically on bibliometric characteristics and indicators of influence.

Design This study reports a bibliometric analysis via a systematic search of the academic literature applying complexity science to healthcare.

Method A search of four academic databases was performed on 19 April 2018. Article details were downloaded and screened against inclusion criteria (peer-reviewed journal articles applying complexity science to healthcare). Publication and content data were then collected from included articles, with analysis focusing on trends over time in the types and topics of articles, and where they are published. We also analysed the influence of this body of work through citation and network analyses.

Results Articles on complexity science in healthcare were published in 268 journals, though a much smaller subset was responsible for a substantial proportion of this literature. USA contributed the largest number of articles, followed by the UK, Canada and Australia. Over time, the number of empirical and review articles increased, relative to non-empirical contributions. However, in general, nonempirical literature was more influential, with a series of introductory conceptual papers being the most influential based on both overall citations and their use as index references within a citation network. The most common topics of focus were health systems and organisations generally, and education, with recent uptake in research, policy, and change and improvement.

Conclusions This study identified changes in the types of articles on complexity science in healthcare published over time, and their content. There was evidence to suggest a shift from conceptual work to the application of concrete improvement strategies and increasingly indepth examination of complex healthcare systems. We also identified variation in the influence of this literature at article level, and to a lesser extent by topic of focus.

\section{BACKGROUND}

Complexity science provides a way of understanding non-linearity, in which causation is problematic and multifaceted, and emergent behaviours are the norm. ${ }^{1}$ It developed out of diverse academic traditions, including computer science, physics, sociology, anthropology,

\section{Strengths and limitations of this study}

- Use of an inclusive search strategy based on previously published reviews and including non-empirical and non-English language articles.

- Articles coded by multiple coders into topic themes to determine popular and emerging areas of interest for complexity science in healthcare.

- A focus on citations and index references as a proxy for influence; citation analysis tends to prioritise older contributions that have had more time to accumulate cites.

- Inclusion of only peer-reviewed articles, minimising the potential influence of some prominent non-peerreviewed contributions.

economics and mathematics. Different systems can be understood using the complexity paradigm-it finds commonalities and patterns in the behaviour of systems comprised of very different agents (ants, cells, humans, societies, species, bacteria), often labelled via a convenient phrase: complex adaptive systems (CASs). ${ }^{2}$ Such systems were initially recognised for displaying 'weird', chaotic and dynamic behaviours; thus, chaos theory was developed to explain such phenomenon. However, a focus only on chaos failed to account for why complex systems also often exhibit degrees of homeostasis-that is, they are somehow balanced between the chaotic and unpredictable on the one hand, and the orderly and predictable on the other-for the most part, most of the time. ${ }^{3}$ Complexity science provides an understanding of systems that are between phase transitions and are often found just 'at the edge of chaos'. ${ }^{13}$

The study of complexity challenges traditional approaches to science that favour a controlled view of the world, where variables are held constant and outcomes are predictable because causes and effects are related, and construed as linear arrangements. ${ }^{4} \mathrm{CASs}$ are not well explained through studies that aim for such reduction, decomposition and cause-effect 
logic, breaking problems down into manageable parts and studying these components individually in an attempt to understand the whole. ${ }^{5}$ In short, CASs are different from and more than the sum of their parts.

Complexity science has pervaded many disciplines, making its way, for example, into the social sciences and the study of human systems and organisations. ${ }^{16}$ The adoption of complexity science principles has been particularly notable in health-related fields, with healthcare systems worldwide recognised as excellent examples of CASs because of the diverse array of agents involved (doctors, patients, nurses, consumer groups, politicians, non-government organisations) and the enormous number of interactions among them. ${ }^{78}$ This work gained momentum at the beginning of this century, with the publication of a number of conceptual contributions discussing the application of complexity science principles in areas of healthcare like clinical practice, ${ }^{9}$ education ${ }^{10}$ and healthcare management. ${ }^{1112}$ Since this time, the potential of complexity science in understanding and tackling some of the otherwise intractable challenges of delivering healthcare-including patient safety, ${ }^{13}$ interprofessional collaboration, ${ }^{14}$ sustained improvement ${ }^{15}$ and managing uncertainty ${ }^{16}$ - has been considered. Empirical studies applying the principles of complexity science to healthcare have also proliferated. Almost two decades ago, Anderson and McDaniel ${ }^{17}$ used complexity theory to understand nurses' decision-making in nursing homes in the USA. Much more recently, Barasa et $a l^{18}$ examined hospitals as CASs in their case study of financing decisions in Kenya.

There are signs that literature on complexity science in healthcare is approaching maturity, with literature reviews of the empirical research now being undertaken, ${ }^{19}$ especially in the context of health services interventions, ${ }^{20}$ as well as publication of a systematic review of empirical and non-empirical complexity ideas. ${ }^{21}$ As a complement to these contributions, now is an appropriate time to examine the influence and spread of this literature in greater detail. Towards this end, bibliometrics is an approach that looks at publication patterns in an area of research literature, including trends over time and globally, and the influence of articles, and the authors and journals publishing such works, indicated by citations.

\section{Aim}

This study aimed to analyse trends in the academic literature on applying complexity science to healthcare, focusing specifically on bibliometric characteristics. We also analysed the influence of this body of work through citation and network analyses.

\section{METHOD}

\section{Systematic search of the literature}

\section{Databases}

On the 19 April 2018, the Cochrane Database of Systematic Reviews, CINAHL, EMBASE and all databases of Web of Science, which includes MEDLINE, were searched using keywords documented below. The general search strategy was based on that taken by Thompson $e a^{19}$ with a range of search terms associated with complexity theory used to account for broad indexing. This included 'chaos theory', because complexity is often described as developing out of, ${ }^{1}$ as well as encompassing the more specific concept of, chaos. ${ }^{22}$ Keywords related to healthcare and health systems were also searched. No date restrictions were used. An example of the search strategy for Web of Science is in online supplementary appendix 1 .

\section{Keywords}

1. 'Complexity theory' OR 'complexity science' OR 'complex adaptive system' OR 'complexity thinking' OR 'complex responsive process theory' OR 'chaos theory'

2. healthcare OR 'health care' OR 'health-care' OR hospital OR 'health facilit*' OR 'acute care' OR 'health organi*' OR 'health system' OR 'primary care' OR 'general practice' OR 'aged care' OR “nurs* home OR medic* OR clinic* OR nurs* OR health

Citations returned from these searches were downloaded into the reference management software Endnote, and duplicates were removed. References were then exported to a Microsoft Excel spreadsheet for screening. Articles were reviewed against inclusion criteria and exclusion criteria by the first author, with a consistency check on $5 \%$ of the references performed by a second author following accepted practices. ${ }^{23}$ References meeting inclusion criteria were classified for bibliometric analysis.

\section{Inclusion and exclusion criteria}

Because we were looking at influence, empirical and non-empirical papers (eg, commentaries, conceptual papers and reviews) published in peer-reviewed academic journals and applying complexity science to healthcare were included in the analysis. We defined healthcare broadly to include not only the professionals involved (eg, nurses, doctors, administrators) and sites of healthcare delivery (eg, hospitals, nursing homes), but also education, policy, processes and ethical or research issues related to healthcare. Health promotion and public health articles were initially retained for full-text screening. However, they were ultimately only included if they discussed healthcare sites, professions or aspects of care delivery, rather than, for example, population-based health promotion interventions and issues.

Letters to the editor and editorial papers that only described the contents of an issue were excluded, because they were not thought to sufficiently contribute to the spread of complexity ideas within healthcare. Books, book chapters and conference proceedings were also excluded because bibliometric data are often not available or incomplete for such publications. Articles that were not originally published in English but provided an English language abstract were included in the bibliometric review if, based on this information, they were found to meet all of the inclusion criteria and none of the exclusion criteria. 


\section{Bibliometric analysis}

Stage 1: review of article publication data

First, bibliometric data on the article, including the year of publication, the journal in which it was published, the corresponding author and their country of residence, were captured from the full text, or the journal or indexing database where full text was unavailable (either inaccessible to the authors or not available in English).

\section{Stage 2: review of article content}

Articles were then classified in greater detail according to their content, including type of article and focus. This involved classifying articles as empirical or non-empirical. The empirical papers were further categorised according to their use of complexity science (eg, prediction, conceptual framework, data analysis or interpretation of findings) following the schema of Thompson et al. ${ }^{19}$ Non-empirical papers were classified as: commentaries and editorials, conceptual discussions, conceptual case studies and protocols. Reviews were also included and classified.

Two of the authors (KC and $\mathrm{CP}$ ) performed a content analysis on the main focus(es) of all the included articles. This involved inductive descriptive coding of each paper, then comparisons, modifications and expansions of codes to identify the most common topic themes in the literature applying complexity science to healthcare. Generally, details in the abstract and title, in addition to database indexing information, were sufficient to classify whether an article was empirical or non-empirical, and also its main focus. However, some articles did not have an abstract, or the abstract detail was insufficient. Full-text review was conducted during this stage (where full text was available in English) to ensure the most accurate classification.

\section{Stage 3: analysis of influence}

The number of citations an article had received over time was used to calculate influence, with citations collected from Google Scholar in July 2018. We also examined influence by identifying one or more 'index' reference(s) for each of the full-text articles reviewed, ${ }^{1}$ where full text was available. An index was defined as the most influential, prominent or leading reference(s) cited by an included article that also focused on complexity science within healthcare (as compared with complexity science in biology, management or generally). However, unlike papers in this review, an index reference need not be a peer-reviewed publication; this criterion allowed us to consider influence from other sorts of academic outputs. Where possible, we identified an index reference based on attribution by the authors of that paper, for example, a statement like: 'In his appendix to Crossing the Quality Chasm, Plsek suggests that, rather than using the principles of mechanical systems to try to improve healthcare, innovators should employ the principles of complex adaptive systems' (page 17). ${ }^{24}$ In the absence of an explicit statement to this effect, we took the first reference(s) cited when introducing the notion of complexity science applied to healthcare. Some of the articles included did not have index references, and others were unable to be searched (ie, full text not available).

Index references and their citing articles were used in a network analysis, visually constructed in Gephi, V.0.9.2. Network analysis uses graph theory to map and measure relationships among nodes. ${ }^{25}$ In this case, the nodes in the network were the articles in the review as well as any index reference(s) they cited, while relationships were directional tie(s) to an index reference (eg, article $\mathrm{X}$ cited article $\mathrm{Y}$ as an index reference). Articles that did not cite an index reference, and were not themselves used as an index reference for another article (ie, an isolate), were removed from the network analysis, on the basis that they did not contribute to understanding influence. In visualising the network, the main topic theme of the research output was used to differentiate different categories of articles and identify any possible clustering, as well as distinguish influential index references that were not captured by our review strategy. The most influential academic outputs in the network were assessed using in-degree calculation (the number of inward directed ties to a node, ie, the number of times an index reference was cited by other articles).

\section{Patient and public involvement}

Neither patients nor members of the public were involved in this study.

\section{RESULTS}

A total of 2505 articles were returned from searches across the four databases and downloaded into Endnote X8. Following removal of duplicates, citation details $(n=2382)$ were exported to Microsoft Excel for screening of their titles and abstracts against inclusion criteria by the first author. To ensure the criteria were clear and could be applied consistently, a second author (LAE) screened a subset $(5 \%)$ of the library. Inter-rater reliability (Cohen's kappa) between the two authors indicated almost perfect agreement $(\kappa=0.88) .{ }^{26}$ Five hundred and forty-seven references were retained, though a further 93 were excluded at stages 1 and 2 of data analysis because, on review, they did not meet inclusion criteria (reasons documented in table 1). This left 454 articles that were subjected to the bibliometric analysis. Figure 1 presents the search strategy.

Of the 454 articles considered eligible for inclusion, the research team was able to access full text in English for 379 articles, permitting a more detailed and accurate classification of content. The remaining 75 articles included in the bibliometric analysis comprised 49 articles in English language journals where full text was inaccessible, and 26 where full text was not available in English. See online supplementary appendix 2 for summary of data extraction. 


\begin{tabular}{ll}
\hline Table 1 Reasons for exclusion at full-text stage \\
\hline Reason for exclusion & $\begin{array}{l}\text { Number of } \\
\text { articles }\end{array}$ \\
\hline Not about complexity science & 12 \\
Not in healthcare & 31 \\
Not a peer-reviewed academic journal article & 49 \\
Article information unable to be found & 1 \\
Total & 93 \\
\hline
\end{tabular}

${ }^{*}$ Rouse WB. Managing complexity: disease control as a complex adaptive system. Information Knowledge Systems Management, 2000, 2 (2), 143-165 was published in a now discontinued journal. Citation data unavailable in Google Scholar, precluding bibliometric analysis.

\section{Stage 1 results: article publication data}

The 454 included articles came from 268 different journals, which were primarily health-focused, but varied in scope. Table 2 displays the journals publishing the highest number of articles in the field. The journal publishing the most articles on complexity science applied to healthcare was the Journal of Evaluation in Clinical Practice $(\mathrm{n}=24)$, followed by Health Care Management Review $(\mathrm{n}=18)$ and Social Science Ẽ Medicine $(\mathrm{n}=11)$.

Using the corresponding author's affiliation as an indicator, we determined that articles applying complexity science principles to healthcare came from 33 countries. USA $(n=199,43.8 \%)$, UK $(n=82,18.1 \%)$, Canada $(n=49$, $10.8 \%)$ and Australia $(n=23,5.1 \%)$ accounted for nearly

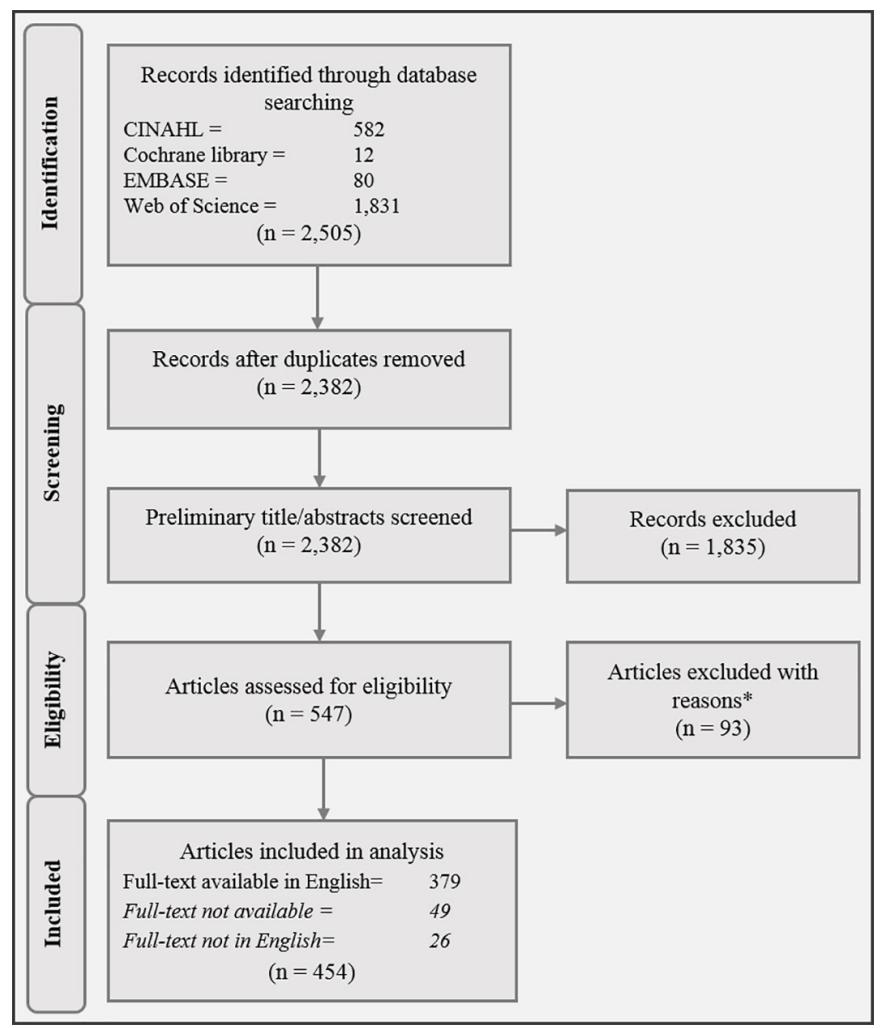

Figure 1 Preferred Reporting Items for Systematic Reviews and Meta-Analyses flow diagram of search strategy.
Table 2 Top 13 journals publishing articles on complexity science applied to healthcare

\begin{tabular}{ll}
\hline $\begin{array}{l}\text { Top journals publishing on complexity science in } \\
\text { healthcare }\end{array}$ & $\begin{array}{l}\text { Number of } \\
\text { articles }\end{array}$ \\
\hline Journal of Evaluation in Clinical Practice & 24 \\
\hline Health Care Management Review & 18 \\
\hline Social Science \& Medicine & 11 \\
\hline BMC Health Services Research & 8 \\
\hline Implementation Science & 8 \\
\hline Journal of Advanced Nursing & 8 \\
\hline Medical Education & 8 \\
\hline Annals of Family Medicine & 6 \\
\hline Academic Medicine & 5 \\
\hline BMJ & 5 \\
\hline International Journal of Integrated Care & 5 \\
\hline Journal of Interprofessional Care & 5 \\
\hline Journal of Nursing Administration & 5 \\
\hline
\end{tabular}

three-quarters of the included papers, as can be seen from figure 2. Other countries contributing substantially were the Netherlands $(n=12,2.6 \%)$ and Brazil $(n=17,3.7 \%)$; for Brazil, this included 11 (2.4\%) papers published in non-English language journals. Despite the concentration of articles among only a few countries, there was evidence for increasing globalisation over time: prior to 2003, the only countries publishing literature on complexity science applied to healthcare were the UK, USA, Canada and Australia, while in 2017-2018, articles came from 16 different countries. These included, for the first time, France, Pakistan, Serbia, Spain and Switzerland.

\section{Stage 2 results: article content}

The majority of the literature $(\mathrm{n}=277,62.8 \%)$ (note, $\mathrm{N}=13$ unable to be classified because full text inaccessible and insufficient information in abstract; \% calculated on 441 articles able to be classified) applying complexity science to healthcare has been non-empirical. Of these, most $(n=178)$ were conceptual discussions of the relevance of complexity science to aspects of healthcare. For example, Fenwick and Dahlgren ${ }^{27}$ considered how complexity principles like emergence and self-organisation apply to simulation-based education in medicine, while Litaker $e t a l^{28}$ advanced the approach for understanding variation in primary care and developing flexible improvement initiatives. Other types of non-empirical articles included: conceptual case studies $(n=39)$, where discussions of complexity science to healthcare were further concretised by real-world examples often based on the authors' prior research (eg, Crabtree et al and Lanham et $a l^{29}{ }^{30}$ ); methodological and practical articles $(n=23)$ focused on methods, models and frameworks to apply complexity science in healthcare (eg, Anderson et al and Normal et $\left.a l^{81}{ }^{32}\right)$; shorter, more opinion-based commentaries and editorials $(\mathrm{n}=18)$; unstructured and narrative reviews $(\mathrm{n}=12)$; and protocol papers $(\mathrm{n}=7)$. 


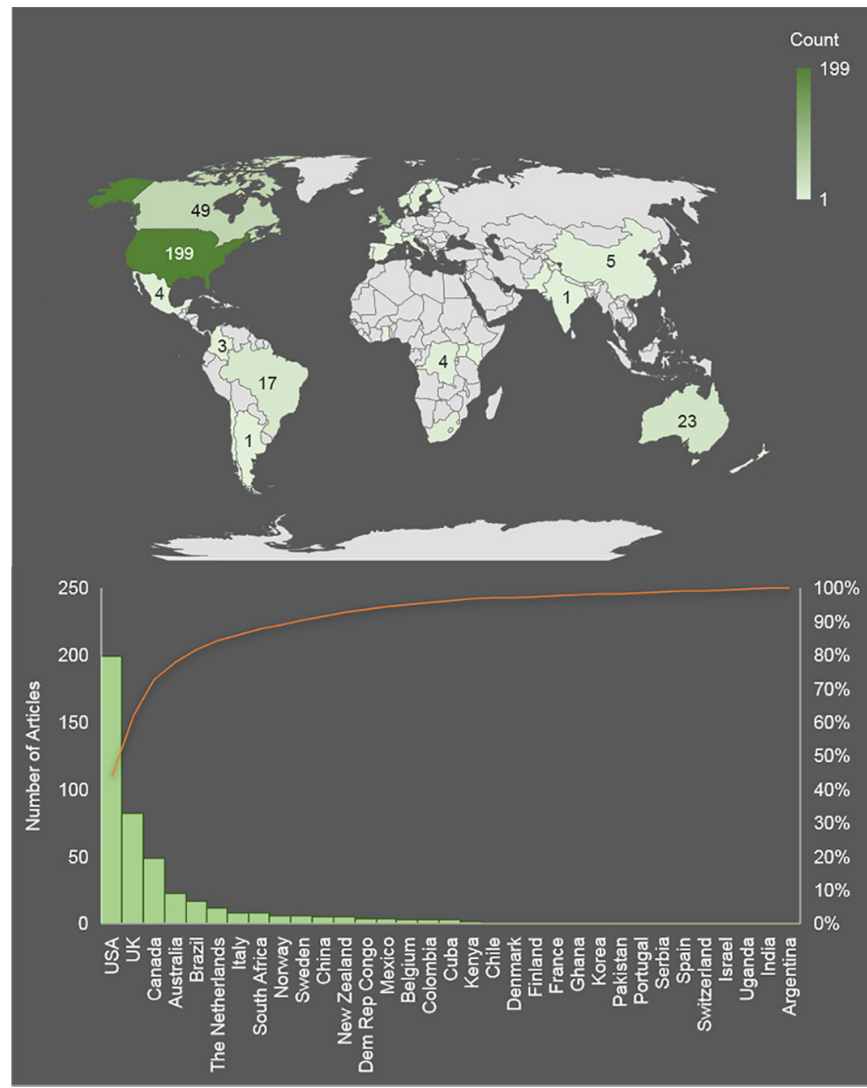

Figure 2 Global trends for publishing articles on complexity science applied to healthcare.

While there were less empirical contributions $(n=149$, $33.9 \%$ ), their publication increased over time, especially over the last 5 years. These empirical articles predominantly employed complexity science as a conceptual framework $(n=109)$, meaning the theory was introduced early in the article to make sense of the problem at hand. Oyeleye $e t a l,{ }^{33}$ in this vein, situated their quantitative study of nurses' burnout and experiences of workplace incivility within a complex adaptive systems framework, noting the paradigms appreciation of individuals' interactions and interconnections, which give rise to unpredictability. In another example, Ssengooba et $a l^{34}$ used a complexity lens in a case study examining the failure of performance-based payment in Uganda, to understand the emergence of new behaviours and adaptation of the healthcare system. To a lesser extent, empirical papers used complexity science for data collection $(n=4)$ or analysis $(n=12)$ where they explicitly linked their design and methods to complexity science principles. For example, Crabtree $e t a l^{35}$ made changes to their study design in order to identify attractors, based on an emerging hypothesis of primary care practices functioning like complex systems. Twenty-two empirical studies used complexity science in a more comprehensive way in the interpretation of the findings of their research (eg, Durie and $\mathrm{Wyatt}^{36}$ ). Full text was unavailable for two empirical articles, and there was not enough detail in the title and abstract to determine use of complexity science.

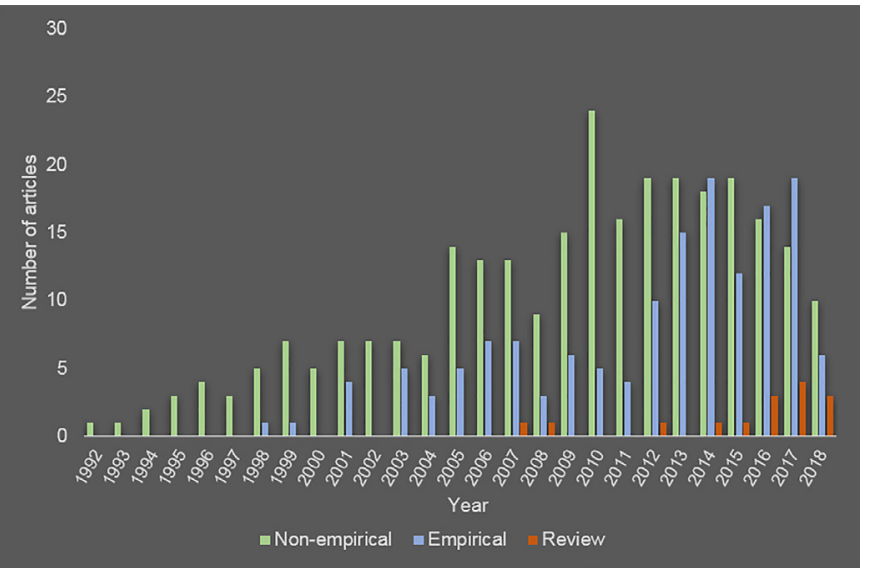

Figure 3 Trends over time in the types of articles published on complexity science applied to healthcare. Note data collected mid-2018.

As well as empirical and non-empirical articles, publication of structured and systematic reviews $(n=15,3.4 \%)$ that either explicitly reviewed complexity science in healthcare (eg, Thompson et al, Brainard and Hunter and Sturmberg et $a l^{192037}$ ) or used these principles as a lens or framework for their review (e.g. Best $e t$ al and Lorthios-Guilledroit $e t a l^{389}$ ) also increased over the last decade. These trends are captured in figure 3.

Delving deeper into the content of these articles, we coded the main focus(es) of each of the articles included in the review, then developed broader categories representing common topic themes for complexity science applied to healthcare. Multiple topic themes were often evident in a single article, so themes are not mutually exclusive. These topic themes are displayed in table 3 . The most common topic themes involved a focus on healthcare settings (especially primary care and hospitals), followed by health systems and organisations generally, healthcare professionals (particularly nursing and medicine) and education. Although healthcare professionals and education were early topics for complexity science in healthcare, it was not until 2006 that these principles were taken up in articles focused on change, improvement and implementation; research; and policy (see figure 4 ).

\section{Stage 3 results: examination of influence Citation analysis}

Influence was calculated using the citations each article received averaged by years elapsed since publication. For the field, this amounted to an overall average of 4.9 citations a year per article, although there was high degree of skewedness $(\mathrm{Mdn}=2.5, \mathrm{Min}=0, \mathrm{Max}=110.1)$ (note, articles published in 2018 not included in calculation). At article level, influence was considered separately for empirical and non-empirical contributions, which included structured reviews. As can be seen in table 4, generally, non-empirical articles were more influential than empirical ones. The most influential article by a substantial margin was the conceptual discussion by Plsek and Greenhalgh, ${ }^{5}$ published in 2001 in the $B M J$, to 
Table 3 Topic themes for articles on complexity science applied to healthcare

\begin{tabular}{|c|c|c|}
\hline Topic themes & $\begin{array}{l}\text { Number of } \\
\text { articles* }\end{array}$ & $\begin{array}{l}\text { Citations per } \\
\text { year }\end{array}$ \\
\hline Management and leadership & 49 & 4.0 \\
\hline Education & 59 & 5.9 \\
\hline $\begin{array}{l}\text { Teamwork, collaboration and care } \\
\text { coordination }\end{array}$ & 31 & 4.8 \\
\hline $\begin{array}{l}\text { Health systems and organisations } \\
\text { generally }\end{array}$ & 76 & 6.0 \\
\hline $\begin{array}{l}\text { Public health and health } \\
\text { promotion }\end{array}$ & 31 & 4.4 \\
\hline Safety, quality and performance & 22 & 2.4 \\
\hline $\begin{array}{l}\text { Change, improvement and } \\
\text { implementation }\end{array}$ & 39 & 5.1 \\
\hline Research & 14 & 4.7 \\
\hline Healthcare policy & 10 & 2.3 \\
\hline Health settings & 146 & 3.4 \\
\hline Aged and nursing care & 21 & 5.7 \\
\hline Ambulatory care & 2 & 0.8 \\
\hline Chronic care & 9 & 4.3 \\
\hline Hospital & 53 & 2.7 \\
\hline Mental health & 6 & 1.9 \\
\hline Paediatrics & 3 & 3.9 \\
\hline Palliative care & 4 & 1.3 \\
\hline Primary care & 48 & 6.4 \\
\hline Healthcare professionals & 71 & 3.6 \\
\hline Allied health & 2 & 0.3 \\
\hline Medicine & 19 & 7.3 \\
\hline Nursing and midwifery & 44 & 2.7 \\
\hline General & 6 & 4.0 \\
\hline Other & 33 & 3.5 \\
\hline
\end{tabular}

*Topic themes are not mutually exclusive, except within subthemes of health settings and healthcare professionals.

introduce a series of papers on complexity in healthcare; numerous other papers in this series also featured in the top 10. A brief description of the main focus of each paper, which was used as the basis for developing topic themes, is present in table 4. For non-empirical articles, the focus tended to be broader and there were a number of common themes, including application of complexity science to healthcare generally, ${ }^{5}$ clinical practice ${ }^{940}$ and education. ${ }^{41}$ The empirical articles were however more varied and specific in focus, though nursing homes and primary care were common areas of interest. Influence was also examined according to the topic themes identified in stage 2; based on this analysis, we found that articles focusing on complexity science specifically in relation to medical professionals were most influential, followed by articles in the primary care setting and considering health systems and organisations generally (table 3).

\section{Network analysis of index references}

The influence of included articles and other research outputs on complexity science applied to healthcare was further investigated in the network analysis of index references, depicted in the sociogram in figure 5 . The network consisted of 514 nodes (ie, academic outputs) and 657 directional ties (which output cited another output as an index reference). Of these nodes, $276(53.7 \%)$ were used as an index reference by at least one other research output in this network (in-degree $>0$ ). The nodes with the highest in-degree are listed in table 5. The most influential node in the network was the article by Plsek and Greenhalgh, ${ }^{5}$ which was cited as an index reference for complexity science in healthcare by 71 other articles in the review. Visualisation revealed an absence of clustering by topic theme; that is, rather than seeing index referencing only between research outputs that explore similar ideas (eg, management only uses other management outputs as index references), there were connections among the different topic themes. There were 183 outputs $(35.6 \%)$ used as index references that had not been included in our review.

\section{DISCUSSION}

Complexity science has brought a radical shift in how we think about many of the dynamic relationships and systems present in our world, with healthcare being no exception. This bibliometric review of complexity science in healthcare has identified trends in the types of articles published over time, and the influence of this body of work. It has documented increasing use of a complex systems lens to describe, understand and study aspects of healthcare over the past two and a half decades, with literature emanating from numerous countries and being published in many journals. There has been considerable concentration, with only a few countries (the USA, UK, Canada and Australia) and journals responsible for a disproportionately high number of contributions; indeed, the way articles are spread across countries shows a feature of complexity in that it approximates a power law distribution. ${ }^{42}$ At the same time, there is evidence of increasing globalisation of complexity science in healthcare literature over the years.

Our findings indicate increases in empirical research and reviews, relative to non-empirical contributions, suggesting a move from the conceptual to the concrete in understanding complexity in healthcare. A recent review by Thompson $e t a l^{19}$ though indicates that empirical work in health services research is often inconsistent and lacks sophistication in the use of complexity science methods; similarly, Brainard and Hunter ${ }^{20}$ reviewed complexity-informed interventions and noted that there is often a poor operationalisation of complexity science principles. In this regard, our own analysis of non-empirical research has identified a preponderance of broad conceptual discussions, rather than practical or methods articles of how to apply complexity science in healthcare. Likewise, 


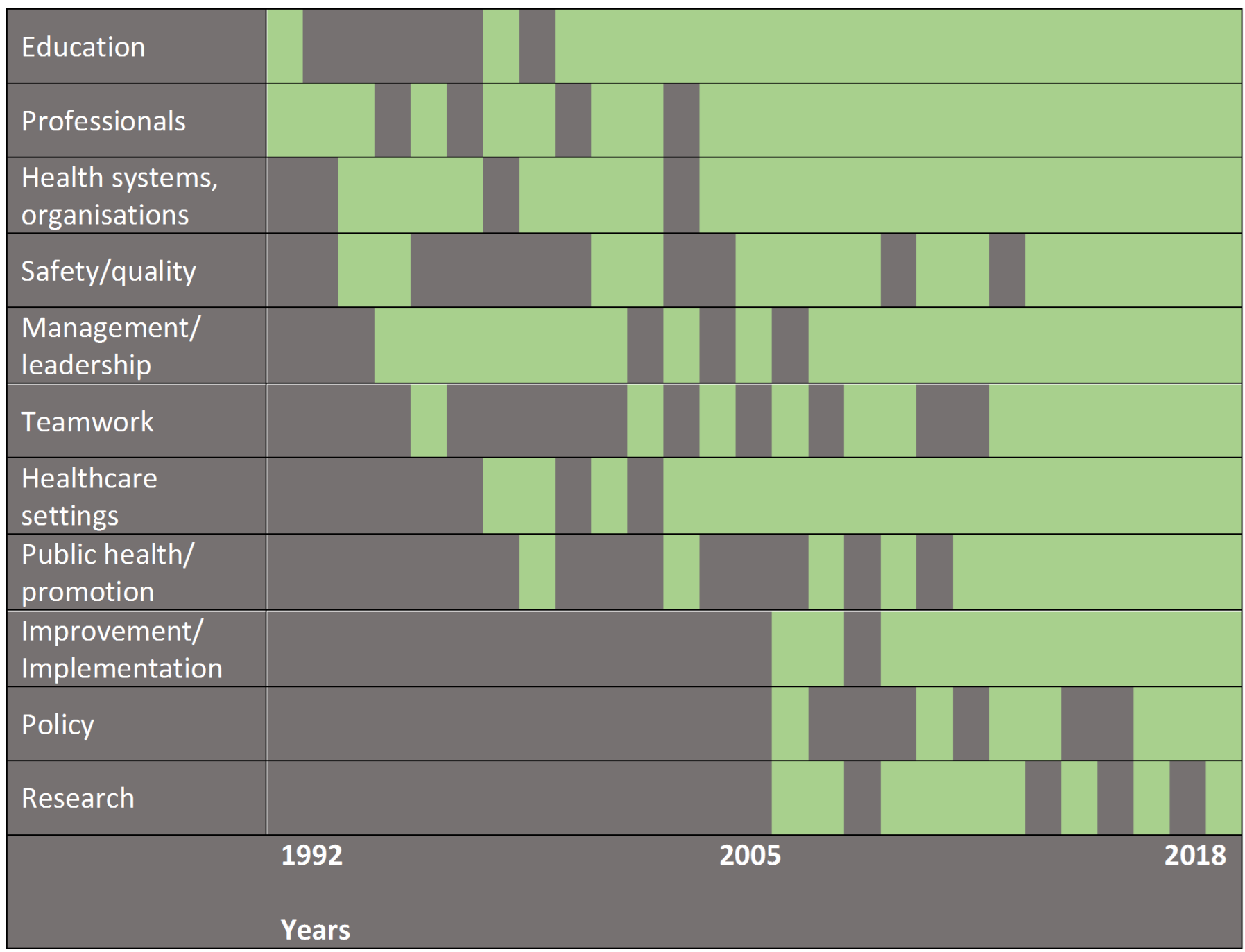

\section{Key}

\section{At least one article published in this year with this topic theme.}

Figure 4 Trend over time in the publications of complexity science applied to healthcare by topic theme.

empirical contributions largely used complexity science to situate their research problem but were less inclined to draw on its tenets in their study design and method.

This bibliometric review further demonstrated that complexity science has permeated diverse contexts and topic areas within healthcare, being particularly prominent in articles on management, education, primary care and hospitals. Interest in research as well as change, improvement and implementation have emerged more recently. In regard to the former, the evolving trend for publishing articles about researching complexity in healthcare suggests increasing awareness of the need to operationalise complexity concepts. Meanwhile, for the latter, a nascent focus on change and improvement mirrors the formalisation of implementation science as a field (eg, Eccles and Mittman ${ }^{43}$ ). It is plausible that these will become more prominent target areas in the future for attention by complexity scientists.

Although there was variation in the degree of influence these topics have had, based on average citations, our network analysis demonstrated limited clustering according to theme, which suggests cross-fertilisation of ideas across the broader body of work on complexity science in healthcare. At the same time, a subset of early contributions on complexity science in healthcare have become widely recognised in the field as the most influential both in terms of their total citations and their consistent status as index references for other articles (eg, Plsek and Greenhalgh, Wilson et al, Fraser and Greenhalgh and Plsek and Wilson ${ }^{5} 91012$ ).

Underscoring the issues this review has identified, in their recent introduction to a series on complexity in medicine and healthcare, Greenhalgh and Papoutsi ${ }^{44}$ argued that despite the proliferation of complexity-informed research, this work has been largely superficial. The radical departure the complexity paradigm was thought to represent in the early 2000s, when the evidently seminal BMJ series was published, has not been carried through in research. The approaches of conventional science-prediction and controlled experiments-are 
Table 4 Most influential empirical and non-empirical articles on complexity science applied to healthcare

\begin{tabular}{|c|c|c|c|c|c|}
\hline Empirical article & $\begin{array}{l}\text { Citations } \\
\text { per year }\end{array}$ & Main focus description & $\begin{array}{l}\text { Non-empirical and } \\
\text { review articles }\end{array}$ & $\begin{array}{l}\text { Citations } \\
\text { per year }\end{array}$ & Main focus description \\
\hline Anderson et $a l^{55}$ & 29.4 & Nursing home & $\begin{array}{l}\text { Plsek and } \\
\text { Greenhalgh }^{5}\end{array}$ & 110.1 & Healthcare - general \\
\hline O'Sullivan et a/ ${ }^{56}$ & 22.6 & $\begin{array}{l}\text { Public health - health } \\
\text { promotion in disaster }\end{array}$ & $\begin{array}{l}\text { Fraser and } \\
\text { Greenhalgh }^{10}\end{array}$ & 50.6 & Education \\
\hline Hanseth et $a l^{57}$ & 21.8 & Hospital - EHR/IT & Plsek and Wilson ${ }^{12}$ & 41.4 & Leadership \\
\hline Oyeleye et $a l^{59}$ & 16.8 & Nursing - workplace bullying & Goldberger $^{40}$ & 39.6 & Clinical practice \\
\hline Anderson et al ${ }^{60}$ & 15.9 & $\begin{array}{l}\text { Nursing homes - job } \\
\text { satisfaction }\end{array}$ & Braa et $a l^{61}$ & 35.6 & $\begin{array}{l}\text { EHR/IT - developing } \\
\text { countries }\end{array}$ \\
\hline Ssengooba et $a l^{34}$ & 15.5 & $\begin{array}{l}\text { Performance targets - health } \\
\text { systems }\end{array}$ & Wilson et $a l^{9}$ & 28.1 & Clinical - general \\
\hline Provost et al ${ }^{13}$ & 14.0 & $\begin{array}{l}\text { Collaboration and teamwork - } \\
\text { safety }\end{array}$ & Anderson et $a l^{31}$ & 25.1 & $\begin{array}{l}\text { Healthcare } \\
\text { organisations }\end{array}$ \\
\hline
\end{tabular}

not appropriate for studying complexity but are still often used. Going forward, in-depth, mixed-method case studies and ethnography, which can understand context

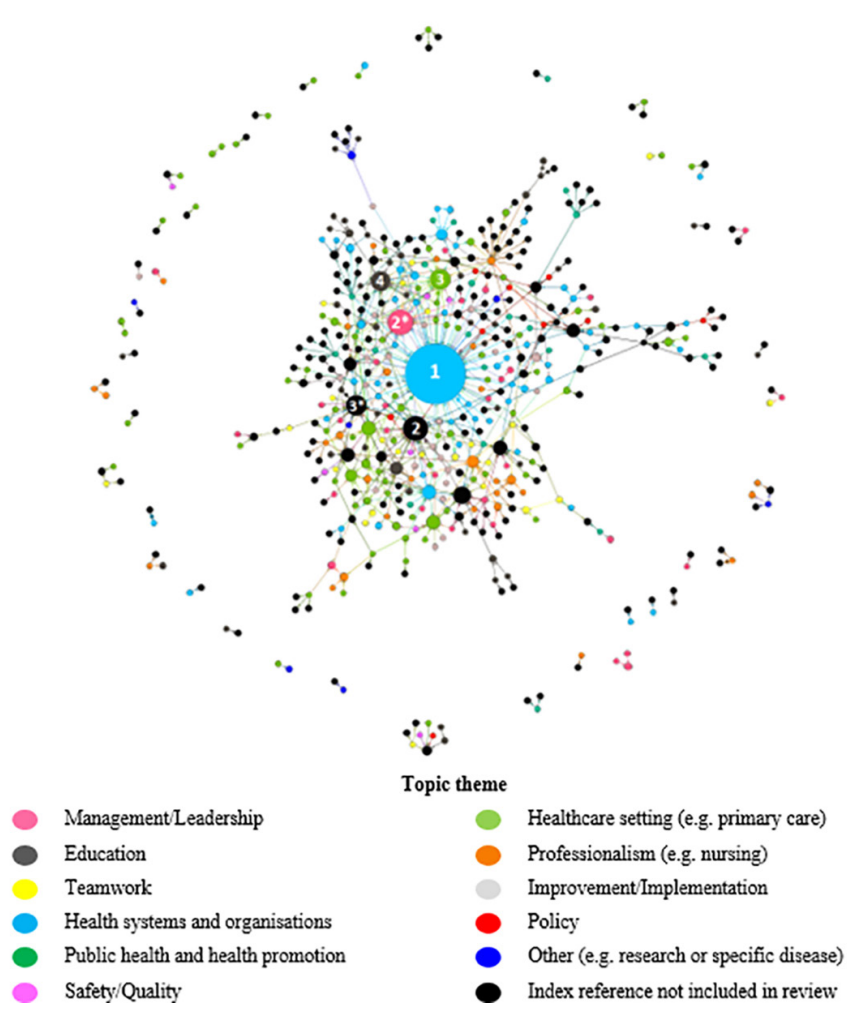

Figure 5 Sociogram of index references for complexity science applied to healthcare. Each circle (node) is representative of a research output. The size of node is indicative of in-degree (larger nodes indicate a higher number of references towards the output as an index). Colour of node is indicative of the topic theme. * indicates equal levels of indegree for corresponding rank. and the interconnectedness of system components, are required, as are new criteria for assessing the quality of complexity-focused research. ${ }^{44}$

\section{Strengths and limitations}

The search strategy for this bibliometric analysis was based on that of a published review. ${ }^{19}$ However, there might be other terms used to denote complexity-focused articles other than those used here; for example, our search did not capture a study of complexity in patient-doctor interactions by Katerndahl and Parchman, ${ }^{45}$ likely because of their preference for the term 'dynamic' and mention of a specific complexity analysis method (orbital dynamics). Therefore, future reviews of complexity should consider this issue in deriving search terms. Our inclusion criteria were designed to be as inclusive as possible, such as in recognising non-English language publications. Peer-reviewed journal articles are best suited to bibliometric

\begin{tabular}{|c|c|c|c|}
\hline \multicolumn{2}{|c|}{$\begin{array}{l}\text { Most popular index } \\
\text { references in network }\end{array}$} & In-degree & \multirow{2}{*}{$\begin{array}{l}\text { Topic theme of } \\
\text { complexity } \\
\begin{array}{l}\text { Health systems and } \\
\text { organisations }\end{array}\end{array}$} \\
\hline 1 & $\begin{array}{l}\text { Plsek and } \\
\text { Greenhalgh }\end{array}$ & 71 & \\
\hline 2 & IOM and Plsek ${ }^{49}$ & 25 & Not in review \\
\hline $2^{\star}$ & Plsek and Wilson ${ }^{12}$ & 25 & $\begin{array}{l}\text { Management/ } \\
\text { leadership }\end{array}$ \\
\hline 3 & Wilson et al ${ }^{9}$ & 19 & Healthcare setting \\
\hline $3^{*}$ & Zimmerman et $\left.a\right|^{48}$ & 19 & Not in review \\
\hline 4 & $\begin{array}{l}\text { Fraser and } \\
\text { Greenhalgh }^{10}\end{array}$ & 18 & Education \\
\hline
\end{tabular}

${ }^{*}$ Indicates equal levels of in-degree. 
and particularly citation analyses, rather than other academic outputs such as books, book chapters and reports, hence this being a requirement for inclusion in our review. ${ }^{46}$ While well justified, our network analysis demonstrates the limits of this approach in that a substantial portion of index references identified were not included in our review, particularly a prominent book by Zimmerman $e t a l^{48}$ and Plsek's appendix to an Institute of Medicine Report. ${ }^{49}$ Despite this limitation, these contributions were included to some extent through our identification of index references.

The citation analysis, as well as our focus on index references, has arguably better illustrated long-term impact than the emerging influence of new and up-and-coming work on complexity science in healthcare, because the publication process can be lengthy, creating delays in the accumulation of citations. ${ }^{50}$ Hence, more recent articles, which we have found influential in guiding our own research, such as those by Leykum, Lanham and their colleagues $^{3051}$ may be revealed as more influential in the coming years. The use of 'altmetrics' (eg, social media mentions) in future bibliometric reviews could facilitate assessment of more immediate impact. ${ }^{52}$ Some contributions influential in the field have straddled public health and social care, such as the work of Hawe ${ }^{53}$ and Sterman, ${ }^{54}$ and so were not included based on our search strategy and inclusion criteria.

\section{CONCLUSION}

This study conducted a bibliometric analysis of the peer-reviewed literature in the evolving academic field of complexity science applied to healthcare. We identified trends in where this work has been conducted and published, including that there is sustained and increasing interest in complexity science, with evident spread of ideas globally and into specific topic areas. There were also clear shifts in the types of articles published over time, and their content. As a field, the application of complexity science to healthcare appears to be increasingly focused on doing complexity-informed research, rather than discussions of its conceptual and theoretical contours. We found substantial variation in the influence of this literature at article level, and to a lesser extent by topic of focus.

Acknowledgements The authors would like to thank Ms Prakriti Kunwar for her assistance in conducting the search, and title/abstract review.

Contributors $\mathrm{KC}$ had the original idea for the article and devised the search strategy with support from LAE, JL and JB. KC oversaw the search, and conducted the title/abstract review and analysis with assistance from CP and LAE. CP performed the network analysis of influence. $\mathrm{KC}$ drafted the manuscript. CP, LAE, JL and JB critically revised the manuscript. All authors agreed upon the final version of the manuscript.

Funding JB is supported by multiple grants, including the National Health and Medical Research Council (NHMRC) Partnership Grant for Health Systems Sustainability (ID: 9100002).

Competing interests None declared.

Patient consent for publication Not required.
Provenance and peer review Not commissioned; externally peer reviewed.

Data sharing statement Data will be shared upon request to the first author.

Open access This is an open access article distributed in accordance with the Creative Commons Attribution Non Commercial (CC BY-NC 4.0) license, which permits others to distribute, remix, adapt, build upon this work non-commercially, and license their derivative works on different terms, provided the original work is properly cited, appropriate credit is given, any changes made indicated, and the use is non-commercial. See: http://creativecommons.org/licenses/by-nc/4.0/.

\section{REFERENCES}

1. Byrne D. Complexity theory and the social sciences: an introduction. London: Routledge, 2002.

2. Chu D, Strand R, Fjelland R. Theories of complexity. Complexity 2003;8:19-30.

3. Waldrop MM. Complexity: the emerging science at the edge of order and chaos: Simon and Schuster, 1993.

4. Dent EB. Complexity science: a worldview shift. Emergence 1999;1:5-19.

5. Plsek PE, Greenhalgh T. Complexity science: the challenge of complexity in health care. BMJ 2001;323:625-8.

6. Stacey RD. The science of complexity: an alternative perspective for strategic change processes. Strategic Management Journal 1995;16:477-95

7. Braithwaite J, Churruca K, Ellis LA. Can we fix the uber-complexities of healthcare? J R Soc Med 2017;110:392-4.

8. Braithwaite J, Churruca K, Ellis LA, et al. Complexity science in healthcare - aspirations, approaches, applications and accomplishments: a white paper. Macquarie University, Sydney, Australia: Australian Institute of Health Innovation, Macquarie University, 2017.

9. Wilson T, Holt T, Greenhalgh T. Complexity science: complexity and clinical care. BMJ 2001;323:685-8.

10. Fraser SW, Greenhalgh T. Complexity science: coping with complexity: educating for capability. BMJ 2001;323:799-803.

11. McDaniel RR, Driebe DJ. In: Savage GT, Friedman LH, Goes J, Complexity science and health care management, in advances in health care management. Bingley, UK: Emerald Group Publishing Limited, 2001:11-36.

12. Plsek PE, Wilson T. Complexity, leadership, and management in healthcare organisations. BMJ 2001;323:746-9.

13. Provost SM, Lanham HJ, Leykum LK, et al. Health care huddles: managing complexity to achieve high reliability. Health Care Manage Rev 2015;40:2-12.

14. Cooper HC, Geyer R. What can complexity do for diabetes management? linking theory to practice. J Eval Clin Pract 2009;15:761-5.

15. Braithwaite J, Churruca K, Long JC, et al. When complexity science meets implementation science: a theoretical and empirical analysis of systems change. BMC Med 2018;16:63.

16. Zimmerman B. Complexity science: a route through hard times and uncertainty. Health Forum J 1999;42:42-69.

17. Anderson RA, McDaniel RR. RN participation in organizational decision making and improvements in resident outcomes. Health Care Manage Rev 1999;24:7-16.

18. Barasa EW, Molyneux S, English M, et al. Hospitals as complex adaptive systems: a case study of factors influencing priority setting practices at the hospital level in Kenya. Soc Sci Med 2017;174:104-12.

19. Thompson DS, Fazio X, Kustra E, et al. Scoping review of complexity theory in health services research. BMC Health Serv Res 2016;16:1-16.

20. Brainard J, Hunter PR. Do complexity-informed health interventions work? A scoping review. Implement Sci 2016;11:127.

21. Rusoja E, Haynie D, Sievers J, et al. Thinking about complexity in health: a systematic review of the key systems thinking and complexity ideas in health. J Eval Clin Pract 2018;24:600-6.

22. Cook RI, Ekstedt M. In: Braithwaite RL, Hollnagel E, Reflections on resilience: repertoires and system features, in resilient health care: reconciling work-as-imagined and work-as-done, J. Boca Raton, FL, USA: CRC Press, Taylor and Francis Group, 2017:111-8.

23. Braithwaite J, Herkes J, Ludlow K, et al. Association between organisational and workplace cultures, and patient outcomes: systematic review. BMJ Open 2017;7:e017708.

24. Kottke TE, Huebsch JA, Mcginnis P, et al. Using principles of complex adaptive systems to implement secondary prevention of coronary heart disease in primary care. Perm J 2016;20:17-24.

25. Wasserman S, Faust K. Social network analysis: methods and applications: Cambridge university press, 1994. 
26. McHugh ML. Interrater reliability: the kappa statistic. Biochem Med 2012;22:276-82.

27. Fenwick T, Dahlgren MA. Towards socio-material approaches in simulation-based education: lessons from complexity theory. Med Educ 2015;49:359-67.

28. Litaker D, Tomolo A, Liberatore $\mathrm{V}$, et al. Using complexity theory to build interventions that improve health care delivery in primary care. $J$ Gen Intern Med 2006;21:S30-4.

29. Crabtree BF, Nutting PA, Miller WL, et al. Primary care practice transformation is hard work: insights from a 15-year developmental program of research. Med Care 2011;49:S28-35.

30. Lanham HJ, Leykum LK, Taylor BS, et al. How complexity science can inform scale-up and spread in health care: understanding the role of self-organization in variation across local contexts. Soc Sci Med 2013;93:194-202.

31. Anderson RA, Crabtree BF, Steele DJ, et al. Case study research: the view from complexity science. Qual Health Res 2005;15:669-85.

32. Norman CD, Charnaw-Burger J, Yip AL, et al. Designing health innovation networks using complexity science and systems thinking: the CoNEKTR model. J Eval Clin Pract 2010;16:1016-23.

33. Oyeleye O, Hanson P, O'Connor N, et al. Relationship of workplace incivility, stress, and burnout on nurses' turnover intentions and psychological empowerment. JONA: The Journal of Nursing Administration 2013;43:536-42.

34. Ssengooba F, McPake B, Palmer N. Why performance-based contracting failed in Uganda-an "open-box" evaluation of a complex health system intervention. Soc Sci Med 2012;75:377-83.

35. Crabtree BF, Miller WL, Stange KC. Understanding practice from the ground up. J Fam Pract 2001;50:881-7.

36. Durie R, Wyatt K. New communities, new relations: the impact of community organization on health outcomes. Soc Sci Med 2007;65:1928-41.

37. Sturmberg JP, Martin CM, Katerndahl DA. Systems and complexity thinking in the general practice literature: an integrative, historical narrative review. Ann Fam Med 2014;12:66-74.

38. Best A, Greenhalgh T, Lewis S, et al. Large-system transformation in health care: a realist review. Milbank Q 2012;90:421-56.

39. Lorthios-Guilledroit A, Richard L, Filiatrault J. Factors associated with the implementation of community-based peer-led health promotion programs: a scoping review. Eval Program Plann 2018;68:19-33.

40. Goldberger AL. Non-linear dynamics for clinicians: chaos theory, fractals, and complexity at the bedside. Lancet 1996;347:1312-4

41. Sargeant J. Theories to aid understanding and implementation of interprofessional education. J Contin Educ Health Prof 2009;29:178-84.

42. Burton C, Elliott A, Cochran A, et al. Do healthcare services behave as complex systems? Analysis of patterns of attendance and implications for service delivery. BMC Med 2018;16:138.

43. Eccles MP, Mittman BS. Welcome to Implementation Science. Implementation Science 2006;1:1.

44. Greenhalgh T, Papoutsi C. Studying complexity in health services research: desperately seeking an overdue paradigm shift. BMC Med 2018;16:95.

45. Katerndahl D, Parchman ML. Dynamical difference in patients encounters involving uncontrolled diabetes: an orbital decomposition analysis. J Eval Clin Pract 2010;16:211-9.
46. Thomson Reuters. Whitepaper - Using bibliometrics: a guide to evaluating research performance with citation data. 2008.

47. De Bellis N. Bibliometrics and citation analysis: from the science citation index to cybermetrics. Lanham, MD: The Scarecrow Press, 2009.

48. Zimmerman B, Lindberg C, Plsek PE. Edgeware: Insights from complexity science for health care leaders. Irving, TX: VHA Publishing, 1998

49. Plsek P. Appendix B: Redesigning health care with insights from the science of complex adaptive systems in Crossing the quality chasm: a new health system for the 21st century: Institute of Medicine, 2001:309-22.

50. Eysenbach G. Can tweets predict citations? Metrics of social impact based on Twitter and correlation with traditional metrics of scientific impact. J Med Internet Res 2011;13:e123.

51. Leykum LK, Lanham HJ, Pugh JA, et al. Manifestations and implications of uncertainty for improving healthcare systems: an analysis of observational and interventional studies grounded in complexity science. Implement Sci 2014;9:165.

52. Barbaro A, Gentili D, Rebuffi C. Altmetrics as new indicators of scientific impact. J Eur Assoc Health Inf Libr 2014;10:3-6.

53. Hawe P. Lessons from complex interventions to improve health. Annu Rev Public Health 2015;36:307-23.

54. Sterman JD. Learning from evidence in a complex world. Am J Public Health 2006;96:505-14.

55. Anderson RA, Issel LM, McDaniel RR. Nursing homes as complex adaptive systems: relationship between management practice and resident outcomes. Nurs Res 2003;52:12-21.

56. O'Sullivan TL, Kuziemsky CE, Toal-Sullivan D, et al. Unraveling the complexities of disaster management: a framework for critical social infrastructure to promote population health and resilience. Soc Sci Med 2013;93:238-46.

57. Hanseth O, Jacucci E, Grisot M, et al. Reflexive Standardization: Side Effects and Complexity in Standard Making. MIS Quarterly 2006;30:563-81.

58. Monrouxe LV, Rees CE, Hu W. Differences in medical students' explicit discourses of professionalism: acting, representing, becoming. Med Educ 2011;45:585-602.

59. Oyeleye O, Hanson P, O'Connor N, et al. Relationship of workplace incivility, stress, and burnout on nurses' turnover intentions and psychological empowerment. J Nurs Adm 2013;43:536-42.

60. Anderson RA, Corazzini KN, McDaniel RR. Complexity science and the dynamics of climate and communication: reducing nursing home turnover. Gerontologist 2004;44:378-88.

61. Braa J, Hanseth O, Heywood A, et al. The flexible standards strategy. MIS Quarterly 2007;31:381-402.

62. Miller WL, McDaniel RR, Crabtree BF, et al. Practice jazz: understanding variation in family practices using complexity science. J Fam Pract 2001;50:872-8.

63. Frye AW, Hemmer PA. Program evaluation models and related theories: AMEE guide no. 67. Med Teach 2012;34:e288-99.

64. Boustani MA, Sachs GA, Alder CA, et al. Implementing innovative models of dementia care: the healthy aging brain center. Aging Ment Health 2011;15:13-22.

65. Bleakley A. Broadening conceptions of learning in medical education: the message from teamworking. Med Educ 2006;40:150-7. 